\title{
The influence of maternal nutrient restriction in early to mid-pregnancy on placental and fetal development in sheep
}

\author{
L. Heasman*, L. Clarke $\dagger$, T. J. Stephenson and M. E. Symonds \\ Academic Division of Child Health, School of Human Development, University Hospital, Queen's Medical Centre, \\ Nottingham NG7 2UH, UK
}

\begin{abstract}
Placental weight is a primary factor determining size at birth in many species. In sheep, placental weight peaks at approximately mid-gestation, with structural remodelling occurring over the second half of pregnancy to meet the increasing nutritional demands of the growing fetus. Numerous factors influence placental growth and development in sheep, and many workers (see Kelly, 1992) have investigated the role of maternal nutrition as a regulator of placental and fetal size. We have studied the effects of feeding ewes approximately $50 \%$ of their recommended energy requirements during early to mid-pregnancy on fetal and placental indices measured at mid-gestation (i.e. $80 \mathrm{~d}$ ) and close to term (i.e. $145 \mathrm{~d}$ ). Maternal nutrient restriction is associated with a reduction in placental weight at $80 \mathrm{~d}$, but an increase in placental weight at $145 \mathrm{~d}$ of gestation, compared with ewes fed adequately in early pregnancy. No significant effect on fetal weight was observed at either 80 or 145 d gestation, although differences in body dimensions and the insulin-like growth factor-1 axis were found in lambs from nutrientrestricted ewes delivered close to term. Maternal nutrition during pregnancy plays a pivotal role in the regulation of fetal and placental development in sheep, and therefore has the potential to influence both short- and longer-term health outcomes.
\end{abstract}

\section{Maternal nutrition: Placenta: Fetus: Adults}

The incidence of morbidity and mortality during the neonatal period is known to be high in babies of low birth weight, but a substantial body of epidemiological evidence now exists to suggest that perturbations in fetal and infant growth rates are also associated with a predisposition to certain disorders in adulthood (Barker et al. 1990). Subsequently, it has become apparent that subtle alterations in conformation at birth, irrespective of birth weight, may also play a role in the programming of future health outcomes (Barker, 1994). The long thin baby, for example, is proposed to be at greater risk of developing hypertension and type 2 diabetes in adulthood, whereas the short fat baby is more likely to develop CHD and thrombotic stroke. The 'fetal and infant origins of adult disease' hypothesis (Barker, 1994) has also been strengthened by data obtained following the Dutch famine of 1944-5 (e.g. Lumey, 1998). Obstetric records have shown reduced birth weights in 'secondgeneration' infants delivered from mothers who themselves had been exposed in utero to the famine in either the first or second trimester of pregnancy (Lumey, 1992). This was found to be due, in part, to a slower fetal growth rate, in conjunction with a shorter gestation. Exposure to famine during the third trimester, however, was not associated with a reduction in birth weight in the second-generation infants, despite the mothers of these infants being themselves growth-retarded at birth. Further evidence for the 'Barker hypothesis' has been derived from numerous animal studies, with cross-breeding experiments demonstrating that the maternal environment is a more important regulator of fetal size than the genetic component (Walton \& Hammond, 1938). More recently, fetal programming of adult hypertension in rats, by maternal nutrition during pregnancy, has been demonstrated by a number of studies (Woodall et al. 1996; Gardner et al. 1998).

\section{Placental development and fetal size}

In the majority of eutherian mammals studied to date, there is a positive correlation between size at birth and placental weight. Pathological alterations in placental weight in

\footnotetext{
Abbreviation: IGF-1, insulin-like growth factor-1.

*Corresponding author: Lindsay Heasman, present address ADAS High Mowthorpe, Duggleby, Malton, North Yorkshire YO17 8BP, UK, fax +44 (0)1944 738434, email Lindsay_Heasman@adas.co.uk

$\dagger$ Present address: School of Biological Sciences, Bourne Building, Royal Holloway and Bedford College, University of London, Egham, Surrey TW20 0EX, UK.
} 
human pregnancies support this finding, with a poorlycontrolled diabetic pregnancy often resulting in a heavy placenta and large infant, while intrauterine growth retardation is associated with a small placenta (Naeye, 1987). The association between placental size and birth weight has been demonstrated clearly in sheep using the carunclectomy technique, where the majority of the discrete sites of placental implantation on the maternal endometrium are surgically removed before mating (Robinson et al. 1979). Although there may be some compensatory growth of the remaining placentomes, the fetus is typically hypoxic and growthretarded.

In sheep, the period of maximal placental weight gain occurs in the first half of gestation, typically between 30 and $80 \mathrm{~d}$ of gestation (Schneider, 1996), with term being $147 \mathrm{~d}$. Peak placental weight is attained by $80 \mathrm{~d}$ of gestation, and placental weight may then decline by up to $30 \%$ over the final $50 \mathrm{~d}$ of pregnancy. Placentome number is generally established by $40 \mathrm{~d}$ of gestation, and is not thought to change throughout pregnancy, although individual placentomes alter in size. Fetal growth rate, however, remains relatively slow until mid-gestation, and it is only after placental weight has peaked that the exponential rise in fetal weight is seen. It is thought that alterations in the structure and morphology of the placenta allow the increasing nutrient requirements of the ovine fetus to be met during late gestation (Schneider, 1996).

\section{Maternal nutrition and placental weight in sheep}

Many studies have examined the effect of maternal nutrition at different stages of pregnancy on placental and fetal development in sheep (see Kelly, 1992). Nutrient restriction over the first $40 \mathrm{~d}$ or final $50 \mathrm{~d}$ of pregnancy generally has no marked effect on placental weight, whereas the majority of studies examining the effect of a restricted diet for periods of variable length between 30 and $107 \mathrm{~d}$ of pregnancy have found placental weight to be markedly altered (Table 1).
However, results obtained are inconsistent, and this may be due to a number of confounding factors, including differences in initial maternal weight, body condition and breed. Furthermore, results obtained at term from nutrientrestricted ewes are generally influenced by a compensatory increase in maternal nutrition over the remainder of pregnancy compared with controls (for example, see McCrabb et al. 1991). In addition, few studies have looked at placental morphology in detail, and effects on fetal conformation have been largely ignored. Other studies have looked at maternal nutrient restriction from 0 to $90 \mathrm{~d}$ of gestation (Everitt, 1964; Rattray \& Trigg, 1979), using a mixture of singleton- and twin-bearing ewes (Mellor \& Murray, 1982), triplets (Kelly $\&$ Ralph, 1988), or measured cotyledon diameter by ultrasound scanning to examine effects on placental development (Kelly et al. 1992; Kleemann et al. 1993). Data from these experiments have not been included in Table 1, as their results are not comparable with those for singleton pregnancies where placental weight data have been obtained (Heasman et al. 1998a).

\section{Maternal nutrient restriction in early to mid-pregnancy}

Given the variation in placental responses to maternal nutrient restriction described previously, we decided to examine, in detail, the effects of a defined alteration in maternal nutritional regimen in early to mid-gestation, over the period of maximal placental growth, on placental and fetal development. Singleton-bearing ewes of similar breed, age and weight at mating were used throughout our studies. These were fed to meet either half or twice their maintenance energy requirements (Agricultural Research Council, 1980) between 30 and $80 \mathrm{~d}$ of gestation, with the diet being increased at $14 \mathrm{~d}$ intervals to meet the higher energy requirements associated with fetal growth. For example, at maintenance levels a $40 \mathrm{~kg}$ ewe would receive $5.62 \mathrm{MJ}$ metabolizable energy/d at $30 \mathrm{~d}$ of gestation, rising to $6 \cdot 22 \mathrm{MJ} / \mathrm{d}$ at $74 \mathrm{~d}$ of gestation (Clarke etal. 1998). For

Table 1. Summary of the effects of maternal nutrient restriction in mid-pregnancy on placental weight in singleton-bearing ewes

\begin{tabular}{|c|c|c|c|c|c|c|c|c|c|}
\hline \multirow[b]{2}{*}{ Reference } & \multirow{2}{*}{$\begin{array}{l}\text { Altered diet } \\
\quad(\mathrm{d} \text { of } \\
\text { pregnancy) }\end{array}$} & \multirow{2}{*}{$\begin{array}{c}\text { Outcome } \\
\text { measured } \\
\text { (d of pregnancy) }\end{array}$} & \multicolumn{2}{|c|}{$\begin{array}{l}\text { Maternal wt } \\
\quad(\mathrm{kg})\end{array}$} & \multicolumn{2}{|c|}{ Nutrition } & \multicolumn{3}{|c|}{ Placental wt (g) } \\
\hline & & & $\mathrm{C}$ & $\mathrm{R}$ & C & $\mathrm{R}$ & $\mathrm{C}$ & $\mathrm{R}$ & $\begin{array}{l}\text { Difference } \\
\quad(\%)\end{array}$ \\
\hline Robinson et al. (1994) & $30-90$ & 90 & 63 & 63 & 'Unrestricted intake' & 'Restricted intake' & 462 & 561 & +21 \\
\hline Robinson et al. (1994) & $30-90$ & 90 & 51 & 51 & 'Unrestricted intake' & 'Restricted intake' & 569 & 423 & -27 \\
\hline McCrabb et al. (1991) & $30-96$ & 96 & 55 & 57 & Fed to gain $100 \mathrm{~g} / \mathrm{d}$ & Fed to lose $114 \mathrm{~g} / \mathrm{d}$ & 496 & 600 & +21 \\
\hline McCrabb et al. (1992b) & $50-96$ & 96 & 45 & 46 & $1.43-1.54 \mathrm{~kg}$ hay $\mathrm{DM} / \mathrm{d}$ & $0.39-0.44 \mathrm{~kg}$ hay $\mathrm{DM} / \mathrm{d}$ & 517 & 488 & -6 \\
\hline McCrabb et al. (1992b) & $75-96$ & 96 & 45 & 46 & $1.43-1.54 \mathrm{~kg}$ hay $\mathrm{DM} / \mathrm{d}$ & $0.44 \mathrm{~kg}$ hay $\mathrm{DM} / \mathrm{d}$ & 517 & 429 & -17 \\
\hline Holst et al. (1992) & $79-107$ & 107 & - & - & Unrestricted pasture & $\begin{array}{l}\text { Pasture restricted (lost } \\
29 \mathrm{~g} / \mathrm{d} \text { ) }\end{array}$ & 433 & 510 & +18 \\
\hline McCrabb et al. (1992b) & $30-96$ & 140 & - & - & $1.43-1.54 \mathrm{~kg}$ hay $\mathrm{DM} / \mathrm{d}$ & $0.39-0.64 \mathrm{~kg}$ hay $\mathrm{DM} / \mathrm{d}$ & 442 & 388 & -12 \\
\hline
\end{tabular}

C, control; R, restricted 
placental and fetal sampling, ewes were humanely killed either at $80 \mathrm{~d}$ of gestation or at $145 \mathrm{~d}$ of gestation following feeding to meet their maintenance energy requirements for the remainder of pregnancy. Each placentome was classified in terms of inversion or apparent overgrowth of fetal tissue within the placentome, as described by Vatnick etal. (1991), with inverted placentomes being classified as A and everted placentomes as B, C or D depending on the extent of eversion. Placentomes were then separated into the maternal and fetal components, which were weighed separately. For ewes studied until term, blood samples were taken through a jugular vein catheter at 77 and $140 \mathrm{~d}$ of gestation, and plasma was analysed to determine cortisol and thyroid hormone concentrations (Clarke et al. 1994; Bird et al. 1996). Furthermore, for ewes studied close to term, cord blood samples were taken at Caesarean section and later analysed for plasma insulin-like growth factor-1 (IGF-1) concentration. Each fetus was dried and weighed, and measurements were taken of crown-rump length, girth (thoracic circumference) and height (Heasman et al. 1998b). Lambs were humanely killed and all major organs were dissected out and weighed.

\section{Maternal thyroid hormones and cortisol}

Maternal nutrient restriction between 28 and $77 \mathrm{~d}$ of gestation had no significant effect on plasma cortisol concentrations at either $77 \mathrm{~d}$ of gestation (controls 90.7 (SE 21.0) nmol/l, $n$ 19; nutrient-restricted 82.2 (SE 15.7) $\mathrm{nmol} / \mathrm{l}, n 28$ ) or $140 \mathrm{~d}$ of gestation (controls 26.4 (SE 10.4) nmol/l, $n$ 19; nutrient-restricted $27 \cdot 7$ (SE 5.1) nmol/l, $n$ 28). At $77 \mathrm{~d}$ of gestation, however, both plasma triiodothyronine and thyroxine concentrations were significantly $(P<0 \cdot 01)$ reduced in the nutrient-restricted group compared with the controls (Fig. 1). Following feeding to maintenance for the remainder of pregnancy, however, plasma thyroid hormone concentrations in the nutrient-restricted group were found not to differ significantly from those of control animals.

\section{Effects on placental morphology}

We have demonstrated that feeding ewes only $50-60 \%$ of their maintenance energy requirements between 30 and $80 \mathrm{~d}$ of gestation results in a decrease in placental weight at $80 \mathrm{~d}$ of gestation, compared with adequately-fed controls (Clarke et al. 1998). By separating each placentome into the maternal caruncular and fetal cotyledonary tissue, we found that this difference is due to a significant $(P<0.05)$ reduction in the weight of the fetal component of the placenta, as the weight of maternal tissue was similar between groups (Fig. 2). Placentome number was found to be significantly higher $(P<0.01)$ in the nutrient-restricted group compared with controls (controls 60 (SE 13), $n$ 5; nutrient-restricted 76 (SE 4), $n 5$ ), although the control group were found to have a greater proportion of large (i.e. $>10 \mathrm{~g}$ ) placentomes, and smaller proportion of placentomes weighing $<8 \mathrm{~g}$ (Clarke et al. 1998). There was no effect of maternal nutrition on placentome type, with the majority in each group being the inverted A type (controls 85.6 (SE 4.5) \%, $n$ 5; nutrientrestricted $81 \cdot 0($ SE 5.5) \%, $n$ 5).
A similar level of maternal nutrient restriction (i.e. 50\%) in early to mid-pregnancy, followed by refeeding to maintenance for the remainder of pregnancy, results in an increase in total placental weight at $145 \mathrm{~d}$ of gestation compared with the controls (Heasman etal. 1998b). This is again due to a difference in the weight of the fetal component of the

(a) Triiodothyronine
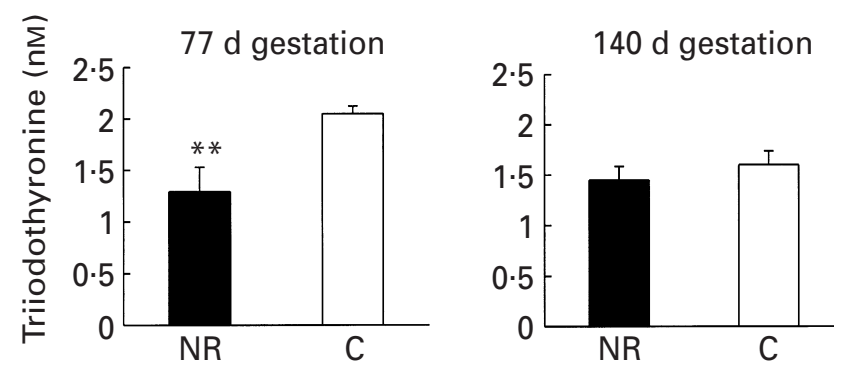

(b) Thyroxine
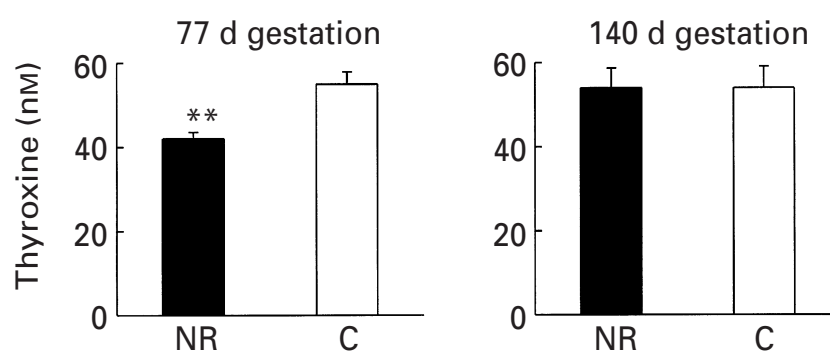

Fig. 1. Maternal plasma thyroid hormone concentrations ((a) triiodothyronine and (b) thyroxine) in nutrient-restricted (NR; (匹); $n$ 28) and control (C; ( $)$ ); $n$ 19) ewes at 77 and $140 \mathrm{~d}$ of gestation. Values are means with their standard errors represented by vertical bars. Mean values were significantly different from those of the controls: ${ }^{* *} P<0 \cdot 01$. For details of procedures, see pp. 284-285.

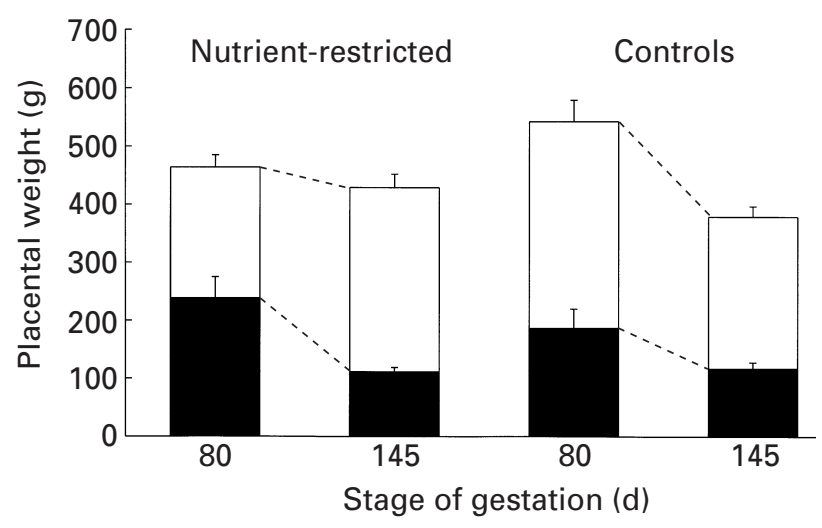

Placental weight $(\mathrm{g})$ at 80 and $145 \mathrm{~d}$ of gestation for nutrient- restricted ( $n 5$ at $80 \mathrm{~d}, n 28$ at $145 \mathrm{~d}$ ) and control ( $n 5$ at $80 \mathrm{~d}, n 19$ at $145 \mathrm{~d}$ ) ewes. Total placental weight is divided into maternal (ם) and fetal ( $\square$ ) components. Values are means with their standard errors represented by vertical bars. For details of procedures, see pp. 284-286. (Adapted from Clarke et al. 1998 and Heasman et al. 1998b). 
placenta, which is approximately $20 \%$ heavier in the nutrient-restricted group compared with the controls (Fig. 2). At $145 \mathrm{~d}$ of gestation, placentome number was again significantly $(P<0.05)$ higher in the nutrientrestricted group (controls 75 (SE 2), $n$ 19; nutrient-restricted 83 (SE 2), $n$ 28), but the distribution of placentome weights was seen to be similar between groups. Placentas from the nutrient-restricted group were found to have fewer inverted A type placentomes (controls 52 (SE 5), $n$ 19; nutrientrestricted 40 (SE 5), $n$ 28; NS), but more of the everted B (controls 7 (SE 2), $n$ 19; nutrient-restricted 13 (SE 2), n 28; $P<0 \cdot 05$ ), C (controls 6 (SE 2), $n$ 19; nutrient-restricted 9 (SE 1), $n$ 28; NS) and D types (controls 9 (SE 3), $n$ 19; nutrient-restricted 20 (SE 5), n $28 P=0 \cdot 09$ ) compared with the controls.

\section{Lamb weight and conformation}

At $80 \mathrm{~d}$ of gestation, maternal nutrient restriction in early to mid-gestation had no significant effect on fetal weight or linear dimensions, including crown-rump length, thoracic circumference or height. All major organs were also found to be similar in weight between groups, with the exception of the brain, which was $2 \mathrm{~g}$ (i.e. $23 \%$ ) lighter in the fetuses of the nutrient-restricted ewes (Fig. 3).

Close to term, fetal weight at Caesarean section delivery was similar between groups, but lambs delivered from ewes subjected to nutrient restriction in early to mid-gestation had significantly $(P<0.01)$ longer crown-rump lengths compared with controls. Again, the level of maternal nutrition in early to mid-gestation had no significant effect on the weight of major organs, including the brain (Fig. 3). This finding suggests that the reduction in brain weight observed in the nutrient-restricted group at $80 \mathrm{~d}$ of gestation can be normalized following adequate nutrition for the second half of pregnancy, although the effects of this normalization on subsequent cerebral function remain to be determined.

IGF-1 is known to be a major determinant of fetal growth, and in particular is thought to regulate the growth of the long bones (Lok et al. 1996). The concentration of IGF-1 in cord blood taken at Caesarean section close to term was not found to differ significantly between groups (controls 96 (SE 10.6) $\mu \mathrm{g} / \mathrm{l}, n$ 19; nutrient-restricted 103 (SE 7.1) $\mu \mathrm{g} / 1, n 28$ ), but a significant positive correlation was found to exist between all body dimensions and cord IGF-1 concentration in the control group $\left(r^{2} \quad 0.58-0.87\right.$, $P<0.001)$, a relationship not present in lambs delivered from nutrient-restricted ewes $\left(r^{2} 0 \cdot 02-0 \cdot 25\right.$; Heasman et al. $1998 c$ ). We suggest this is evidence that the fetal IGF-1 growth axis is sensitive in utero to alterations in the maternal metabolic environment, and hypothesize that an alternative endocrine factor may regulate the growth of fetuses delivered from nutrient-restricted ewes.

\section{Future perspectives}

The level of nutrition in early to mid-pregnancy clearly influences placental development in sheep, and also has effects on fetal conformation, although fetal weight is not affected. These findings may be due directly to nutritionally-mediated alterations in maternal endocrine status, such as the reduced levels of circulating thyroid hormones observed following nutrient restriction, or indirectly by a reduction in fetal substrate supply, possibly in conjunction (a) $80 \mathrm{~d}$ of gestation

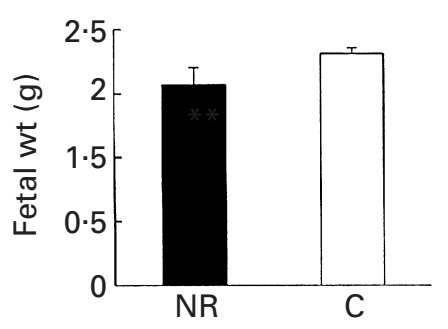

(b) $145 \mathrm{~d}$ of gestation

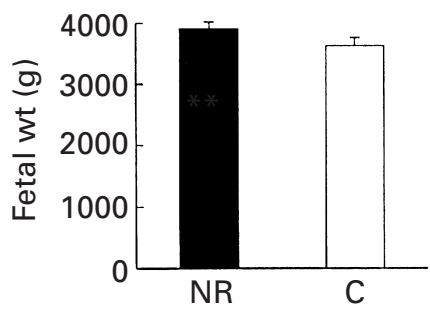

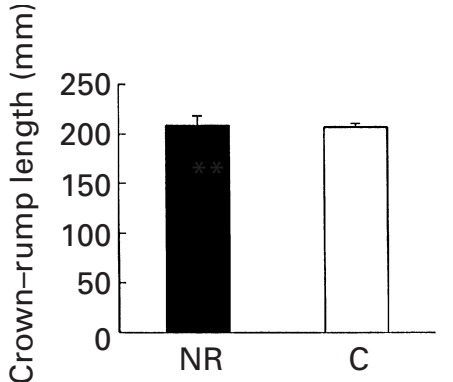

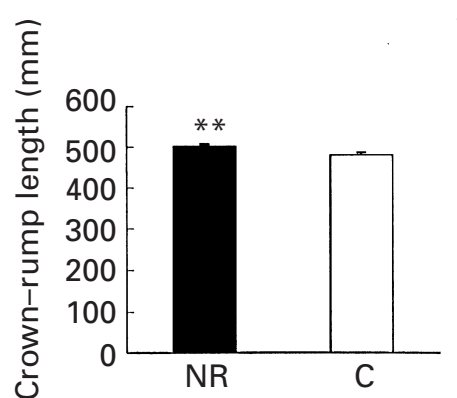

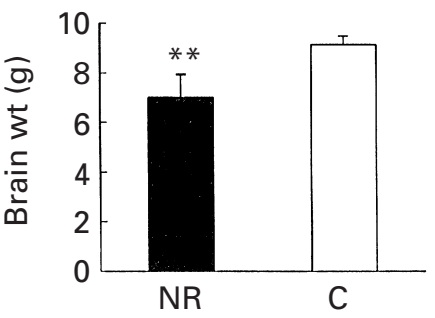

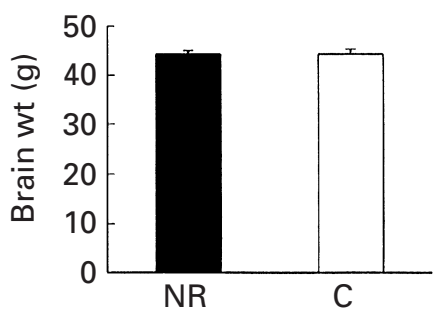

Body weight, crown-rump length and brain weight at (a) $80 \mathrm{~d}$ of gestation and (b) $145 \mathrm{~d}$ of gestation of fetuses delivered from nutrient-restricted (NR; (-); $n 5$ at $80 \mathrm{~d}, n 28$ at $145 \mathrm{~d}$ ) and control (C; (); $n 5$ at $80 \mathrm{~d}, n 19$ at $145 \mathrm{~d}$ ) ewes. Values are means with their standard errors represented by vertical bars. Mean values were significantly different from those of the controls: $* * P<0.01$ For details of nrocedures see nn 384-386 (Adanted from Clarke ot al 1098 and 
with altered fetal and/or placental hormone production. Attention is now being focused on the consequences of altered placental development on both short- and long-term outcome measures. A preliminary study has found that lambs delivered by Caesarean section from ewes subjected to nutrient restriction in early to mid-pregnancy are unable to thrive when delivered into a cool ambient temperature, but that treatment with an umbilical vein injection of thyrotrophin-releasing hormone before cord clamping greatly improves survival rates (Symonds et al. 1998). A longerterm follow-up study by Kelly et al. (1996) has also shown that poor nutrition during fetal life has the potential to reduce both the quantity and quality of wool in young Merino sheep.

The concept of fetal programming is now well established in the fields of medical and biomedical research, and the role of maternal nutrition during pregnancy as a mediator of such programming is becoming increasingly recognized. Advanced molecular biology techniques have been able to show differences in gene transcription (Ozanne et al. 1997) and enzyme activity (Langley-Evans et al. 1996) in specific tissues between fetuses from mothers fed differentially during pregnancy, but the role of the placenta in these adaptations is poorly understood. Furthermore, the mechanisms whereby alterations in the metabolic environment of the fetus are able to translate into adult disease syndromes remain to be determined. It is clear, however, that only by gaining an in-depth knowledge of the interactions between maternal body reserves, nutrition during pregnancy and placental function, can important issues for both animal welfare and human disease be addressed.

\section{Acknowledgements}

The authors acknowledge the financial support of the Wellcome Trust and the Ministry of Agriculture, Fisheries and Food.

\section{References}

Agricultural Research Council (1980) The Nutrient Requirements of Ruminant Livestock, pp. 115-119. Slough, Berks: Commonwealth Agricultural Bureaux.

Barker DJP (1994) Mothers, Babies and Disease in Later Life. London: BMJ Publishing Group.

Barker DJP, Bull AR, Osmond C \& Simmonds SJ (1990) Fetal and placental size and risk of hypertension in adult life. British Medical Journal 301, 259-262.

Bird JA, Spencer JAD, Mould T \& Symonds ME (1996) Endocrine and metabolic adaptation following caesarean section or vaginal delivery. Archives of Disease in Childhood 74, F132-F134.

Clarke L, Darby CJ, Lomax MA \& Symonds ME (1994) Effect of ambient temperature during 1st day of life on thermoregulation in lambs delivered by cesarean section. Journal of Applied Physiology 76, 1481-1488.

Clarke L, Heasman L, Juniper DT \& Symonds ME (1998) Maternal nutrition in early-mid gestation and placental size in sheep. British Journal of Nutrition 79, 359-364.

Davis SR, Rattray PV, Petch ME \& Duganzich DM (1981) Interrelationships of placental development with nutrition in pregnancy and lamb birth weight. Proceedings of the New Zealand Society of Animal Production 41, 218-223.
Everitt GC (1964) Maternal undernutrition and retarded foetal development in Merino sheep. Nature 201, 1341-1342.

Faichney GJ \& White GA (1987) Effects of maternal nutritional status on fetal and placental growth and on fetal urea synthesis in sheep. Australian Journal of Biological Science 40, 365-377.

Gardner DS, Jackson AA \& Langley-Evans SC (1998) The effect of prenatal diet and glucocorticoids on growth and systolic blood pressure in the rat. Proceedings of the Nutrition Society 57, 235240.

Heasman L, Clarke L, Dandrea J, Stephenson T \& Symonds ME (1998a) Influence of fetal number on placental mass and lamb conformation at term in sheep. Contemporary Reviews in Obstetrics and Gynaecology (In the Press).

Heasman L, Clarke L, Firth K, Stephenson T \& Symonds ME (1998b) Influence of restricted maternal nutrition in early to mid gestation on placental and fetal development at term in sheep. Pediatric Research 44, 546-551.

Heasman L, Stephenson T \& Symonds ME (1998c) Impact of maternal nutrient restriction in early to mid gestation on lamb size and insulin-like growth factor-1 (IGF-1) status at term. Proceedings of the Nutrition Society 57, 124A.

Holst PJ, Allan CJ \& Gilmour AR (1992) Effects of a restricted diet during mid pregnancy of ewes on uterine and fetal growth and lamb birth weight. Australian Journal of Agricultural Research 43, 315-324.

Kelly RW (1992) Nutrition and placental development. Proceedings of the Nutrition Society of Australia 17, 203-211.

Kelly RW, Macleod I, Hynd P \& Greeff J (1996) Nutrition during fetal life alters annual wool production and quality in young Merino sheep. Australian Journal of Experimental Agriculture 36, 259-267.

Kelly RW \& Ralph IG (1988) Lamb and wool production from ewes fed differentially during pregnancy. Proceedings of the Australian Society of Animal Production 17, 218-221.

Kelly RW, Speijers EJ, Ralph IG \& Newnham JP (1992) Lambing performances and wool production of maiden and adult Merino ewes fed different amounts of lupin seed in mid-pregnancy. Australian Journal of Agricultural Research 43, 339-354.

Kleemann DO, Walker SK, Walkley JRW, Ponzoni RW, Smith DH, Grimson RJ \& Seamark RF (1993) Effect of nutrition during pregnancy on fetal growth and survival in $\mathrm{FEC}^{\mathrm{B}}$ Booroola $\mathrm{x}$ South Australian Merino ewes. Theriogenology 39, 623-630.

Langley-Evans SC, Gardner DS \& Jackson AA (1996) Maternal protein restriction influences the programming of the rat hypothalamic-pituitary-adrenal axis. Journal of Nutrition 126, $1578-1585$.

Lok F, Owens JA, Mundy L, Robinson JS \& Owens PC (1996) Insulin-like growth factor 1 promotes growth selectively in fetal sheep in late gestation. American Journal of Physiology 270, R1148-R1155.

Lumey LH (1992) Decreased birthweights in infants after maternal in utero exposure to the Dutch famine of 1944-1945. Paediatric and Perinatal Epidemiology 6, 240-253.

Lumey LH (1998) Compensatory placental growth after restricted maternal nutrition in early pregnancy. Placenta 19, 105-111.

McCrabb GJ, Egan AR \& Hosking BJ (1991) Maternal undernutrition during mid-pregnancy in sheep. Placental size and its relationship to calcium transfer during late pregnancy. British Journal of Nutrition 65, 157-168.

McCrabb GJ, Egan AR \& Hosking BJ (1992a) Maternal undernutrition during mid-pregnancy in sheep: variable effects on placental growth. Journal of Agricultural Science 118, 127-132.

McCrabb GJ, Hosking BJ \& Egan AR (1992b) Changes in the maternal body and feto-placental growth following various lengths of feed restriction during mid-pregnancy in sheep. Australian Journal of Agricultural Research 43, 1429-1440. 
Mellor DJ \& Murray L (1982) Effects of long term undernutrition of the ewe on the growth rates of individual fetuses during late pregnancy. Research in Veterinary Science 32, 177-180.

Naeye RL (1987) Do placental weights have clinical significance? Human Pathology 18, 387-391.

Ozanne SE, Nave BT, Wang CL, Shepherd PR, Prins J \& Smith GD (1997) Poor fetal nutrition causes long-term changes in expression of insulin signalling components in adipocytes. American Journal of Physiology 273, E46-E51.

Rattray PV \& Trigg TE (1979) Minimal feeding of pregnant ewes Proceedings of the New Zealand Society of Animal Production 39, 242-250.

Robinson JS, Kingston EJ, Jones CT \& Thorburn GD (1979) Studies on experimental growth retardation in sheep. The effect of removal of endometrial caruncles on fetal size and metabolism. Journal of Developmental Physiology 1, 379-398.

Robinson JS, Owens JA, De Barro T, Lok F \& Chidzanja S (1994) Maternal nutrition and fetal growth. In Early Fetal Growth and Development, pp. 317-329 [RHT Ward, SK Smith and D Donnai, editors]. London: RCOG Press.

Schneider H (1996) Ontogenic changes in the nutritive function of the placenta. Placenta 17, 15-26.

Symonds ME, Heasman L, Clarke L, Firth K \& Stephenson T (1998) Maternal nutrition and disproportionate placental to fetal growth. Biochemical Society Transactions 26, 91-96.

Vatnick I, Schoknecht PA, Darrigrand R \& Bell AW (1991) Growth and metabolism of the placenta after unilateral fetectomy in twin pregnant ewes. Journal of Developmental Physiology 15, 351-356.

Walton A \& Hammond J (1938) The maternal effects on growth and conformation in Shire horse-Shetland pony crosses. Proceedings of the Royal Society of London 125B, 311-335.

Woodall SM, Johnston BM, Breier BH \& Gluckman PD (1996) Chronic maternal undernutrition in the rat leads to delayed postnatal growth and elevated blood pressure of offspring. Pediatric Research 40, 438-443. 